\title{
Cascade system using both trough system and dish system for power generation
}

\author{
Cheng Zhang ${ }^{1}$, Yanping Zhang',a), Inmaculada Arauzo², Wei Gao ${ }^{1}$, Chongzhe Zou ${ }^{1}$ \\ ${ }^{1}$ School of Energy and Power Engineering, Huazhong University of Science and Technology, Wuhan, China \\ ${ }^{2}$ CIRCE Research Institute, University of Zaragoza, Maria de Luna, Zaragoza, Spain \\ a)Corresponding author: zyp2817@hust.edu.cn
}

\begin{abstract}
This paper represents a novel solar thermal cascade system using both trough and dish systems for power generation. An effective structure using the condensed fluid of Rankine cycle to cool the Stirling engines to use the heat released by Stirling engines was proposed. The cascade system model with different fluid circuits was developed. The models of some important components of the system, such as dish collector, trough collector and Stirling engine array, are presented with detail explanation in this paper. Corresponding stand-alone systems were also developed for comparison. Simulations were conducted with the models to find out efficiency difference between cascade system and corresponding stand-alone systems. The directions to increase the efficiency difference were also considered. Results show that the cascade system can achieve a higher efficiency with a high solar irradiance ( $\left.>550 \mathrm{~W} / \mathrm{m}^{2}\right)$. The flow type of fluids between heating and cooling Stirling engine array is also required to concern on designing a cascade system with Stirling engine array.
\end{abstract}

Keywords: cascade system, dish receiver, trough collector, Stirling engine array

\section{Introduction}

Energy is the crucial part for the infrastructure and maintenance of society. With the increase amount of energy consumption, our quality of life has been improved significantly. However, nowadays the world energy consumption is highly dependent on fossil fuels, which supplied $81.2 \%$ of the world's energy consumption in 2013 according to the data of World Bank Group. [1] Using fossil fuels a lot is afflicting the environment, which is sacrificing our quality of life. Environmental pollutions and global warming are becoming serious problems, and it is urgent to find clean and renewable energy to substitute the fossil fuels.

Solar energy is a clean, sustainable, wide-distributed energy. However, solar energy has some disadvantages for its low flux density and large fluctuation due to daily and seasonal variations exacerbated by variations owing to weather. Concentrated solar power (CSP) technology has the ability to overcome these disadvantages and believed to be the future power generation technology. [2] There are 3 common commercial forms of CSP technologies, parabolic trough, dish Stirling and solar power tower, each with their advantages and disadvantages with different suitable working temperature zones. Combination of different collectors and/or cycles with different technologies may provide a new direction to achieve higher efficiency with lower cost for CSP. 


\begin{tabular}{|c|c|c|c|}
\hline \multicolumn{4}{|c|}{ Nomenclature } \\
\hline$\dot{m}$ & Mass flow rate, $\mathrm{kg} / \mathrm{s}$ & $T_{a m b}$ & Ambient temperature, $\mathrm{K}$ \\
\hline$A$ & Area, $\mathrm{m}^{2}$ & $T_{s, d}$ & Designed mean steam temperature of turbine, \\
\hline \multirow[t]{2}{*}{$A_{s e, 1}$} & Heat transfer area of Stirling engine at air side, & & $\mathrm{K}$ \\
\hline & 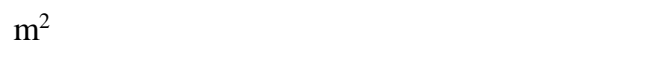 & $U$ & Overall heat transfer coefficient, $\mathrm{W} /\left(\mathrm{m}^{2} \cdot \mathrm{K}\right)$ \\
\hline \multirow[t]{2}{*}{$A_{s e, 2}$} & Heat transfer area of Stirling engine at water & $V_{a m b}$ & Ambient wind speed, $\mathrm{m} / \mathrm{s}$ \\
\hline & side, $\mathrm{m}^{2}$ & $w$ & Width, m \\
\hline \multirow[t]{2}{*}{$c_{p}$} & Heat capacity of Stirling engine working gas at & $x$ & Dryness fraction \\
\hline & constant pressure, $\mathrm{J} /(\mathrm{kg} \cdot \mathrm{K})$ & $y$ & Extraction rate of steam turbine \\
\hline \multirow[t]{2}{*}{$c_{v}$} & Heat capacity of Stirling engine working gas at & \multicolumn{2}{|c|}{ Abbreviations } \\
\hline & constant volume, J/(kg·K) & CSP & Concentrated Solar Power \\
\hline$d$ & Diameter, m & ISCC & Integrated Solar Combined Cycle \\
\hline dep & Depth, m & LFC & Linear Fresnel Collector \\
\hline \multirow[t]{2}{*}{$e$} & Regeneration effectiveness of the Stirling & ORC & Organic Rankine Cycle \\
\hline & engine & PTC & Parabolic Trough Collector \\
\hline$F_{e}$ & Soiling factor of the trough collector & SRC & Steam Rankine Cycle \\
\hline$I_{r}$ & Direct Normal Irradiance, $\mathrm{W} / \mathrm{m}^{2}$ & \multicolumn{2}{|c|}{ Greek Symbols } \\
\hline$K$ & Incidence angle modifier of trough collector & $\beta$ & Ratio of power of Stirling engines to the total \\
\hline$k$ & Specific heat ratio & & output power of cascade system \\
\hline$n$ & Number of collectors & $\delta$ & Thickness, m \\
\hline$n_{1}$ & Number of columns of the Stirling engine array & $\varepsilon$ & Emissivity \\
\hline$n_{2}$ & $\begin{array}{l}\text { Number of rows of the Stirling engine } \\
\text { array }\end{array}$ & $\eta_{\text {diff }}$ & $\begin{array}{l}\text { Efficiency difference of cascade system and } \\
\text { stand-alone systems, } \eta_{c s}-\eta_{s}\end{array}$ \\
\hline$n_{g}$ & Amount of working gas in each engine, mol & $\eta_{\text {shading }}$ & Shading factor \\
\hline \multirow[t]{2}{*}{$n_{s e}$} & Number of Stirling engines in the Stirling & $\gamma$ & Intercept factor; compression ratio \\
\hline & engine array & $\lambda$ & Thermal conductivity, W/(m·K) \\
\hline$P$ & Power, W & $\phi$ & Incidence angle \\
\hline$p_{c}$ & Exhaust pressure of turbine, $\mathrm{Pa}$ & $\rho$ & Reflectivity \\
\hline$p_{s}$ & Main steam pressure of turbine, $\mathrm{Pa}$ & $\theta_{d c}$ & Dish aperture angle $\left(0^{\circ}\right.$ is horizontal, $90^{\circ}$ is \\
\hline$p_{a m b}$ & Ambient pressure, $\mathrm{Pa}$ & & vertically down) \\
\hline$q ”$ & Heat flux, W/m² & Subscr & pts \\
\hline$S_{s e}$ & Speed of Stirling engine, $\mathrm{s}^{-1}$ & $c$ & Counterflow \\
\hline$T_{H}$ & Highest temperature of expansion space, $\mathrm{K}$ & $C S$ & Cascade system \\
\hline$T_{L}$ & Lowest temperature of compression space, $\mathrm{K}$ & $d c$ & Dish collector \\
\hline$T_{R}$ & Regenerator temperature, $\mathrm{K}$ & $d e$ & Deaerator \\
\hline$T_{s}$ & Main steam temperature of the turbine, $\mathrm{K}$ & $g e$ & Generator \\
\hline
\end{tabular}




\begin{tabular}{|llll|}
\hline$i$ & Isentropic; inlet & sea & Stirling engine array \\
insu & Insulating layer & $t c$ & Trough collector \\
$p$ & Parallel flow & $x$ & Stirling engine in column $\mathrm{x}$ \\
$\mathrm{pu}$ & Pump & 1 & First fluid (Air) \\
$\mathrm{s}$ & Stand-alone systems & 2 & Second fluid (Water) \\
se & Stirling engine & & \\
\hline
\end{tabular}

Many researchers have done the work on the combination of different thermodynamic cycles for CSP. Lots of the work focused on integrated solar combined cycle (ISCC) with parabolic trough, where Rankine cycle is used as the bottom cycle. Li and Yang [3] proposed a novel two-stage ISCC system that could reach up to 30 \% of the net solarto-electricity efficiency. In their research, the impact on the system overall efficiencies of how and where solar energy is input into ISCC system was investigated. Behar et al. [4] reviewed the R\&D activities and published studies since the introduction of such a concept in the 1990s. One of the conclusions is that the higher the solar radiation intensity the better is the performance of the ISCCS than those of conventional CSP technologies. Gülen [5] used the exergy concept of the second law of thermodynamics to distil the complex optimization of ISCCS to its bare essentials. After the exergy analysis, physics-based, user-friendly guidelines were provided to help direct studies involving heavy use of time consuming system models in a focused manner and evaluate the results critically to arrive at feasible ISCC designs. Shaaban [6] introduced a novel ISCC with steam and organic Rankine cycles. The ORC was used in order to intercool the compressed air and produce a net power from the received thermal energy. The proposed cycle performance was studied and optimised with different ORC working fluids. Alqahtani and Dalia [7] quantified the economic and environmental benefits of an ISCC power plant relative to a stand-alone CSP with energy storage, and a natural gas-fired combined cycle plant. Results show that integrating the CSP into an ISCC reduces the LCOE of solar-generated electricity by 35-40\% relative to a stand-alone CSP plant, and provides the additional benefit of dispatch ability. Manente [8] developed a 390MWe three pressure level natural gas combined cycle to evaluate different integration schemes of ISCC. Both power boosting and fuel saving operation strategies were analysed in the search for the highest annual efficiency and solar share. Result shown that, compared to power boosting, the fuel saving strategy shows lower thermal efficiencies of the integrated solar combined cycle due to the efficiency drop of gas turbine at reduced loads. Rovira et al. [9] compared the annual performance and economic feasibility of ISCC using two solar concentrating technologies: parabolic trough collectors (PTC) and linear Fresnel collectors (LFC). 
Different configurations were considered and results shown that only evaporative configuration is the most suitable choice. Compared with traditional ISCC design, two new conceptual hybrid designs for ISCC with parabolic trough were represented by Turchi et al. [10]. In the first design, gas turbine waste heat is supplied for both heat transfer fluid heating and feed water preheating. In the second design, gas turbine waste heat is supplied for a thermal energy storage system. Mukhopadhyay and Ghosh [11] presented a conceptual configuration of a solar power tower combined heat and power plant with a topping air Brayton cycle. The conventional gas turbine combustion chamber is replaced with a solar receiver. A simple downstream Rankine cycle with a heat recovery steam generator and a process heater have been considered for integration with the solar Brayton cycle. Li et al. [12] presented a novel cascade system using both steam Rankine cycle (SRC) and organic Rankine cycle (ORC). Screw expander is employed in the steam Rankine cycle for its good applicability in power conversion with steam-liquid mixture. The heat released by steam condensation is used to drive the ORC. Al-Sulaiman [13] compared the produced power of an SRC-ORC combined cycle with traditional SRC cycle. The SRC is driven by parabolic trough solar collectors, and the ORC cycle is driven by the condensation heat of the SRC. This combined cycle is a typical cascade utilisation of the solar energy, which uses the condensation heat of the top Rankine cycle to drive a bottom Rankine cycle. Bahari et al. [14] considered the optimisation of an integrated system using organic Rankine cycle to utilise the heat released by the Stirling cycle. However, the integrated system is a primitive design and it takes no consideration of applications in CSP field.

However, very few researches have been done on the combination of different types of collectors for CSP. Desai et al. [15] presented an integrated CSP plant configuration with the combination of both PTC and LFC. Thermoeconomic comparisons between PTC-based, LFC-based and integrated CSP plant configurations, without hybridisation and storage, were analysed. It is demonstrated that the cost of energy of an integrated CSP plant is 9.6\% cheaper than PTC-based CSP plant and 13.5\% cheaper than LFR-based CSP plant. Coco et al. [16] developed four different line-focusing solar power plant configurations integrated both direct steam generation and Brayton power cycle. In these configurations, collectors are divided into different solar fields to supply different heat demands. This provides the ability to use different types of collectors (parabolic trough and linear Fresnel) in the systems.

The literature review indicates that CSP configuration with combination of different types of collectors and thermodynamic cycles has not been reported till now. In this paper, a cascade system using both Stirling cycle and Rankine cycle, which integrates both parabolic trough and parabolic dish collectors, is proposed. Parabolic trough collectors are used to collect lower temperature energy with lower cost and dish collectors are used to collect higher 
temperature energy with higher efficiency. Rankine cycle is used to work in lower temperature zone and Stirling cycle is used to work in higher temperature zone. Effective topological structures are considered to take full advantages of thermodynamic characters of different components of the system. The Stirling engines are cooled by condensed fluid of Rankine cycle to use the heat released by Stirling engines.

First, the idea of cascade system is presented and the feasibility analysis of the system is performed. A conceptual sketch of the system is presented with some important state points. Second, based on this sketch, some components are chosen and some key parameters of the system are given. Third, models of components are developed according to their thermodynamic properties. Models of different circuits are developed with these component models and efficiency can be obtained by the circuit data. Fourth, two stand-alone systems, dish-Stirling system and troughRankine system, are developed for comparison. At last, the models of the systems are calculated and results are analysed.

\section{System description and specification}

In the cascade system, dish collectors are used to provide heat for Stirling engines and air-to-water heat exchanger. Trough collectors are used to provide heat for steam generating processes (preheating, evaporating and superheating) in the Rankine cycle. Figure 1 shows the scheme sketch of the cascade system. In this system, hot air is produced by the dish collectors. High temperature (1073 K) air is used to provide heat to Stirling cycle to get higher conversion efficiency, then the air is used to provide heat for air-to-water heat exchanger to use the lower temperature energy in Rankine cycle effectively. Besides, feed water of Rankine cycle is used to cool the Stirling engines to recycle the heat wasted conventionally. 


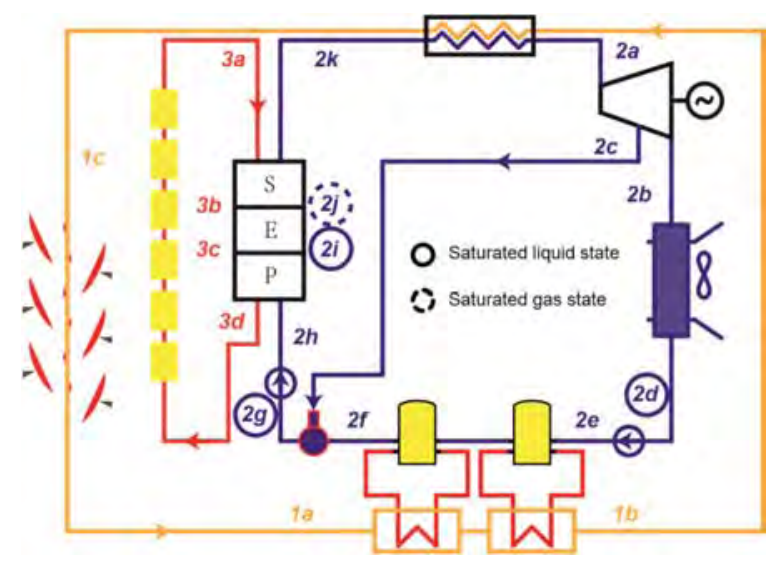

Fig. 1. Sketch of the cascade system

State points of different fluids are marked on the sketch. The number indicates the type of the fluid, the letter indicates the state point of the fluid. State points with solid circle indicate saturated liquid states $(x=0)$, and with dotted circle indicates saturated gas states $(x=1)$. Figure 2(a) shows the $T-s$ diagram of the water circuit in the cascade system. In this Rankine cycle, the heat provided in process $2 e-2 f$ comes from the Stirling engines, which increases the power of Rankine cycle. Figure 2(b) shows the heat transfer diagram of this process.



(a) $T-s$ diagram of the water circuit

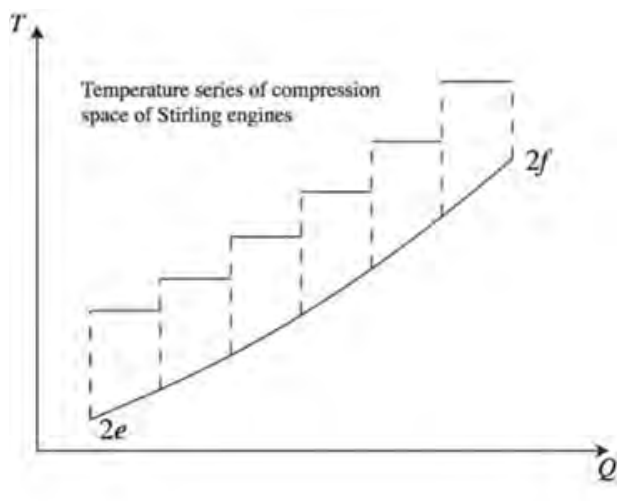

(b) Heat transfer diagram of process $2 e-2 f$

Fig. 2. Diagrams of water circuit and 2e-2f process

To build the cascade system model, several simplifying assumptions are made:

- Steady state at nominal load of the system is analysed.

- Pressure drop due to flow is negligible. 
- The leak of working fluid in the pipes is neglected.

- $\quad$ Same isentropic efficiency of steam turbine with different loads and in different stages.

- Heat loss that occurs from the tube to the atmosphere is not considered.

- There is no heat loss to the environment for Stirling engines.

- Simple models are used of some processes and equipment.

- A symmetrical regenerator behaviour is assumed so that a single effectiveness can be defined as $e=\left(T_{R}\right.$ $\left.T_{L}\right) /\left(T_{H}-T_{L}\right)[17,18]$.

- A linear temperature profile across the regenerator exists, the mean effective temperature $T_{R}=\left(T_{H}-\right.$ $\left.T_{L}\right) /\left(\ln \left(T_{H} / T_{L}\right)\right)[19,20]$

Table 1 shows the basic design parameters of the cascade system.

\begin{tabular}{cccccc}
\multicolumn{5}{c}{ Table 1 Basic design parameters of the cascade system } \\
\hline Parameter & Value & Parameter & Value & Parameter & Value \\
\hline$I_{r}$ & $700 \mathrm{~W} / \mathrm{m}^{2}$ & $T_{d c, o}$ & $1073 \mathrm{~K}$ & $n_{s e}$ & 100 \\
$T_{a m b}$ & $293 \mathrm{~K}$ & $p_{d c}$ & $5 \times 10^{5} \mathrm{~Pa}$ & $T_{s}$ & $613 \mathrm{~K}$ \\
$p_{a m b}$ & $1 \times 10^{5} \mathrm{~Pa}$ & $\Delta T_{3,2, m i n}$ & $15 \mathrm{~K}$ & $p_{s}$ & $2.35 \times 10^{6} \mathrm{~Pa}$ \\
$v_{a m b}$ & $4 \mathrm{~m} / \mathrm{s}$ & $T_{t c, o}$ & $623 \mathrm{~K}$ & $p_{c}$ & $1.5 \times 10^{4} \mathrm{~Pa}$ \\
$P_{g e}$ & $6 \times 10^{6} \mathrm{~W}$ & $p_{t c}$ & $2 \times 10^{6} \mathrm{~Pa}$ & $T_{s, d}$ & $663 \mathrm{~K}$ \\
$T_{d c, i}$ & $623 \mathrm{~K}$ & $T_{1 b}$ & $673 \mathrm{~K}$ & $p_{d e}$ & $1 \times 10^{6} \mathrm{~Pa}$ \\
\hline
\end{tabular}

\section{System model}

An EES (Engineering Equation Solver) model was developed to investigate the characteristics of the cascade system. Three circuits, air circuit, water circuit and oil circuit, were developed with some specific state parameters in some key components. Energy-based models of these key components were created on the basis of their thermodynamic behaviour, heat transfer and the second law. The following parts introduce models of some key components.

\subsection{Dish collector}

A dish reflector product of SES (Stirling Energy System) is used in this cascade system, and its key parameters are listed in Table 2 . 


\begin{tabular}{cccccc}
\hline Parameter & Value & Parameter & Value & Parameter & Value \\
\hline$d_{\text {cav }}$ & $0.46 \mathrm{~m}$ & $\varepsilon_{\text {insu }}$ & 0.6 & $\theta_{d c}$ & $45^{\circ}$ \\
$\delta_{\text {insu }}$ & $0.075 \mathrm{~m}$ & $\alpha_{\text {cav }}$ & 0.87 & $\gamma$ & 0.97 \\
dep $_{\text {cav }}$ & $0.23 \mathrm{~m}$ & $\delta_{a}$ & $0.005 \mathrm{~m}$ & $\eta_{\text {shading }}$ & 0.95 \\
$d_{a p}$ & $0.184 \mathrm{~m}$ & $d_{i, 1}$ & $0.07 \mathrm{~m}$ & $\rho$ & 0.91 \\
$\lambda_{\text {insu }}$ & $0.06 \mathrm{~W} /(\mathrm{m} \cdot \mathrm{K})$ & $A_{d c}$ & $87.7 \mathrm{~m}^{2}$ & & \\
\hline
\end{tabular}

Fraser, in his dissertation [21], developed a performance prediction model of dish-Stirling system with detailed description. The model is also used in the software SAM (System Advisor Model), which provides performance and financial models for facilitate decision in the renewable energy industry. Based on this model, a dish receiver model considered thermal losses is developed in this paper. Figure 3 shows the structure and thermal network of the dish receiver. The thermal network of dish receiver concerns the losses:

- $\quad$ Radiation losses out of the receiver through the aperture. $\left(q_{\text {rad,ref }}\right)$

- $\quad$ Conductive losses through the receiver insulating layer. $\left(q_{\text {cond,tot }}\right)$

- $\quad$ Free convection from the cavity in the absence of wind. ( $\left.q_{\text {conv,free }}\right)$

- $\quad$ Forced convection in the presence of wind. $\left(q_{\text {conv,forc }}\right)$

- Emission losseLs due to thermal radiation emitted from the receiver aperture. $\left(q_{\text {rad,emit }}\right)$

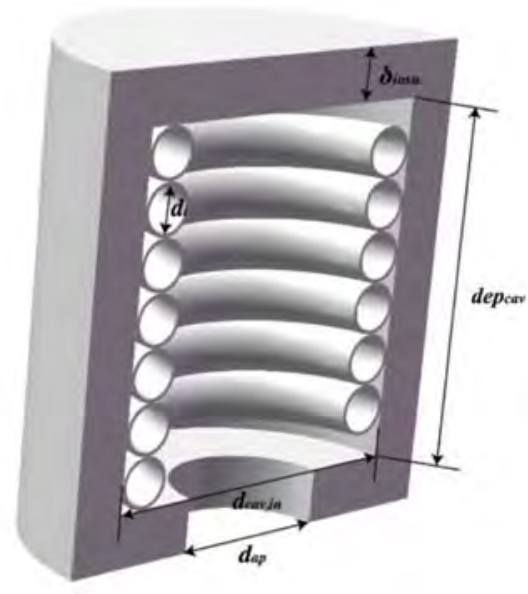

(a) Structure

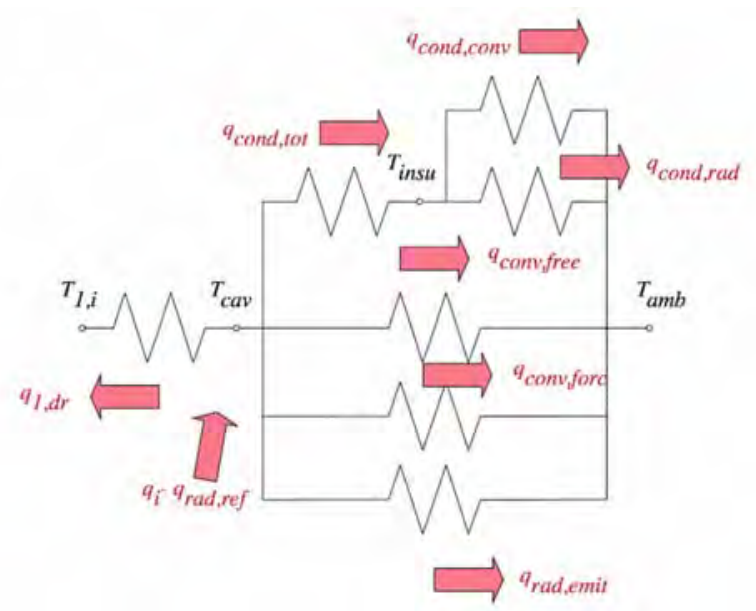

(b) Thermal network

Fig. 3. Structure and thermal network of dish receiver 


\subsection{Trough collector}

LUZ solar collector LS-3 is used as the trough collector. The heat flux to the outer surface of the receiver can be obtained by $q^{\prime \prime}=I_{r} w_{t c} \eta_{o p t, 0} K(\phi) F_{e} / P$, where $P=\pi d_{o}, K(\phi)$ is the incidence angle modifier, $\eta_{o p t, 0}=\rho \gamma \tau \alpha_{a b s}$ is peak optical efficiency (optical efficiency with an incidence angle of 0 ).

Assume overall heat transfer coefficient $U\left(T_{a b s}\right)$ is uniform for whole length of the collector, and the heat transfer correlation in Appendix A can be used.

$$
\frac{T_{o}-T_{a m b}-\frac{q^{\prime \prime}}{U\left(T_{a b s}\right)}}{T_{i}-T_{a m b}-\frac{q^{\prime \prime}}{U\left(T_{a b s}\right)}}=\exp \left(-\frac{U\left(T_{a b s}\right) P L}{\dot{m} c_{p}}\right)
$$

Since the Nu number in the pipe is very large (about $1 \times 10^{4}$ ), small temperature difference exists between the absorber and oil. So $\left(T_{i}+T_{o}\right) / 2$ can be used as the average value of $T_{a b s}$, and $U\left(T_{a b s}\right)$ can be obtained by the a secondorder polynomial function given by Romero [22]. The length L required to get the required number of trough collectors in a row can be obtained from Equation (1).

\subsection{Stirling engine array}

Stirling engine array is used in the cascade system, Fig. 4 shows the layout of the Stirling engine array. Each Stirling engine in the Stirling engine array has the identical parameters: $U_{s e, 1}=30 \mathrm{~W} /\left(\mathrm{m}^{2} \cdot \mathrm{K}\right), U_{s e, 2}=150 \mathrm{~W} /\left(\mathrm{m}^{2} \cdot \mathrm{K}\right)$, $A_{s e, 1}=6 \mathrm{~m}^{2}, A_{s e, 2}=6 \mathrm{~m}^{2}, k_{s e}=1.4, \gamma_{\mathrm{se}}=3.375, n_{g}=7.84 \times 10^{-2} \mathrm{~mol}, \mathrm{~s}_{s e}=10 \mathrm{~s}^{-1}$.

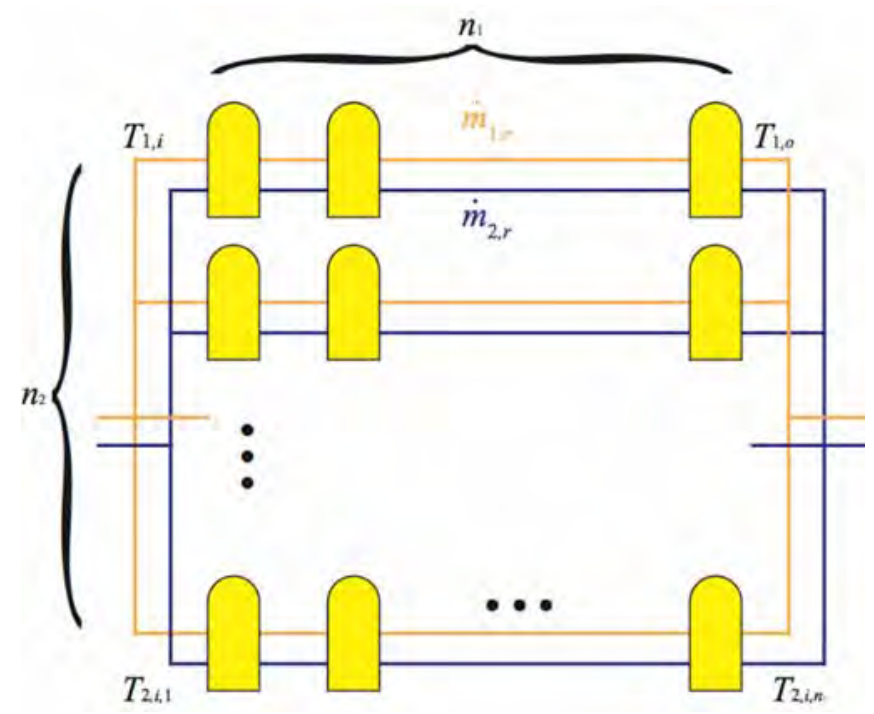


Fig. 4. Layout of Stirling engines

Depending on the direction of heating and cooling flows, there are two possible flow types: parallel flow and counterflow. Figure 5 shows the heat transfer diagrams of the two flow types.

In Fig. $4, T_{1, i, 1}=T_{1, i}, \dot{m}_{1, r}=\dot{m}_{1} / n_{2}$. For $x$ from 1 to $n_{1}-1$, where $x$ is the column number of Stirling engines, $T_{1, i, x+1}=T_{1, o, x}, T_{2, i, x+1}=T_{2, o, x}$.

Assume that the positive flow direction is to the right, for parallel flow, $T_{2, i, 1}=T_{2, i}, \dot{m}_{2, r}=\dot{m}_{2} / n_{2}$; for counterflow, $T_{2, o, n_{1}}=T_{2, i}, \dot{m}_{2, r}=-\dot{m}_{2} / n_{2}$.

For a Stirling engine in column $x, x$ from 1 to $n_{1}$, according to Appendix B,

$$
\begin{gathered}
T_{H, x}=T_{1, i, x}-\frac{T_{1, i, x}-T_{1, o, x}}{1-\exp \left(-\frac{U_{s e, 1} A_{s e, 1}}{\dot{m}_{1, r} c_{p, 1, x}}\right)} \\
T_{L, x}=T_{2, i, x}-\frac{T_{2, i, x}-T_{2, o, x}}{1-\exp \left(-\frac{U_{s e, 2} A_{s e, 2}}{\dot{m}_{2, r} c_{p, 2, x}}\right)}
\end{gathered}
$$

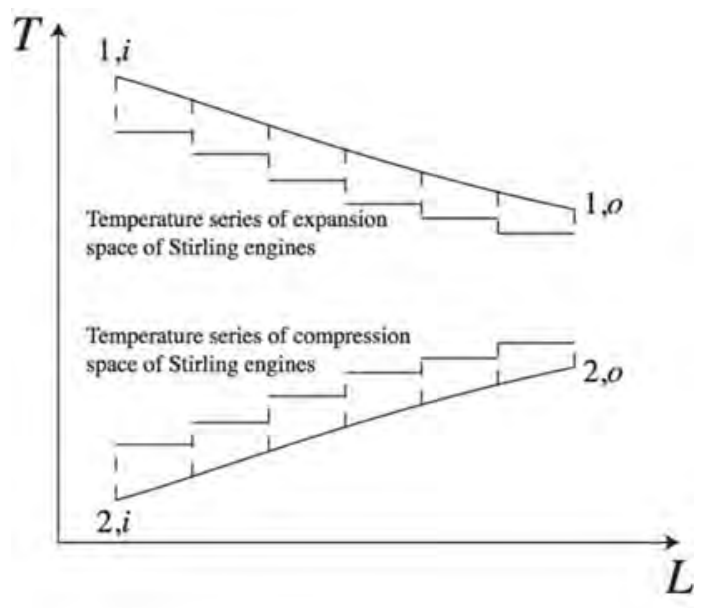

(a) Parallel flow

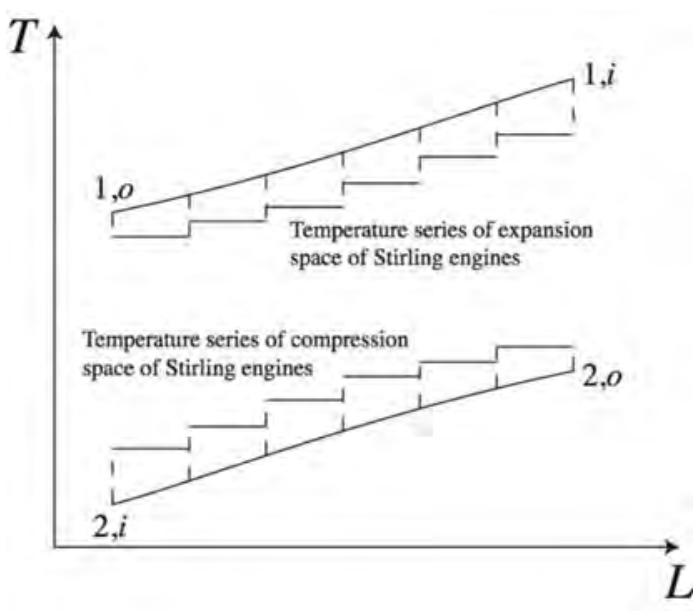

(b) Counterflow

Fig. 5. Heat transfer diagram of parallel flow and counterflow 
The efficiency of each Stirling engine in column $x$ can be written as $\eta_{s e, x}=\frac{T_{H, x}-T_{L, x}}{T_{H, x}+\frac{1-e_{x}}{k-1} \cdot \frac{T_{H, x}-T_{L, x}}{\ln \gamma_{s e}}}$, where $e_{x}=\frac{T_{R, X}-T_{L, X}}{T_{H, X}-T_{L, X}}[23,18]$ and $T_{R, X}=\frac{T_{H, X}-T_{L, X}}{\ln \left(T_{H, X} / T_{L, X}\right)}[19,20]$.

For energy balance,

$$
\dot{m}_{1, r}\left(h_{1, i, x}-h_{1, o, x}\right)\left(1-\eta_{s e, x}\right)=\dot{m}_{2, r}\left(h_{2, o, x}-h_{2, i, x}\right)
$$

And in each Stirling cycle, the heat absorbed by the working gas is

$$
n_{g} R\left(T_{H, x} \ln \gamma_{s e}+\frac{1-e_{x}}{k-1}\left(T_{H, X}-T_{L, x}\right)\right)=\dot{m}_{1, r}\left(h_{1, i, x}-h_{1, o, x}\right) / s_{s e}
$$

By solving above equations, efficiency of the Stirling engine array $\eta_{\text {sea }}$ can be obtained by $\eta_{s e a}=1-\frac{\dot{m}_{2}\left(h_{2, o, n_{1}}-h_{2, i, 1}\right)}{\dot{m}_{1}\left(h_{1, i, 1}-h_{1, o, n_{1}}\right)}$, power of each Stirling engine in column $x, P_{s e, x}=\dot{m}_{1, r}\left(h_{1, i, x}-h_{1, o, x}\right) \eta_{s e, x}$, and power of the Stirling engine array $P_{\text {sea }}=\eta_{\text {sea }} \dot{m}_{1}\left(h_{1, i, 1}-h_{1,0, n_{1}}\right)$.

The presented Stirling engine model is a simplified one. Although the simplified model of the Stirling engine doesn't affect the idea of solar thermal cascade system presented in this paper, more accurate Stirling engine model can be applied to achieve higher accuracy in the future work.

\subsection{Steam turbine}

A steam turbine product, N-6 2.35, of Qingdao Jieneng Power Station Engineering Co., Ltd is used for calculation. Its isentropic efficiency $\eta_{i, t b}$ can be obtained by the given design parameters.

Using basic design parameters in Table 1, parameters of state $2 b$ and $2 c$ in Fig. 1 of the steam turbine can be obtained by $\eta_{i, t b}=\left(h_{2 a}-h_{2 b}\right) /\left(h_{2 a}-h_{i, 2 b}\right)=\left(h_{2 a}-h_{2 c}\right) /\left(h_{2 a}-h_{i, 2 c}\right)$.

The output power of steam turbine $P_{t b}=(1-y) \dot{m}_{2}\left(h_{2 a}-h_{2 b}\right)+y \dot{m}_{2}\left(h_{2 a}-h_{2 c}\right)$.

The total power of pumps $P_{p u}=(1-y) \dot{m}_{2}\left(h_{2 e}-h_{2 d}\right)+\dot{m}_{2}\left(h_{2 h}-h_{2 g}\right)$.

Heat injected in the water circuit $Q_{2}=(1-y) \dot{m}_{2}\left(h_{2 f}-h_{2 e}\right)+\dot{m}_{2}\left(h_{2 a}-h_{2 h}\right)$.

The efficiency of Rankine cycle can be expressed as $\eta_{r k}=\left(P_{t b}-P_{p u} / \eta_{g e}\right) / Q_{2}$. 


\section{Stand-alone system models}



(a) Stand-alone trough-Rankine system

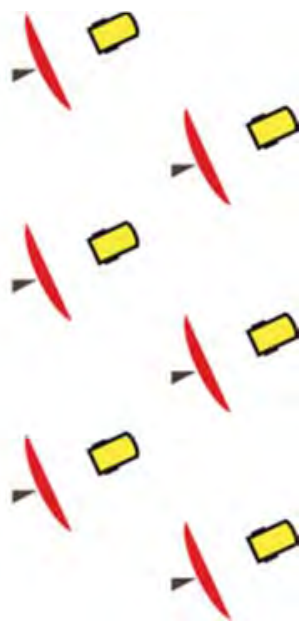

(b) Stand-alone dish-Stirling system

Fig. 6. Sketch of the stand-alone systems

Figure 6 shows the sketch of the stand-alone systems. These two stand-alone systems were developed for comparison. They use the same dish collectors and trough collectors with the same thermal efficiencies.

\subsection{Stand-alone trough-Rankine system}

Steam turbine has the same main parameters and isentropic efficiency with that of the cascade system. Pressure of deaerator are the same of the cascade system. So parameters of state $2 b, s$ and $2 c$, $s$ in Fig. 6 of the steam turbine can be obtained by $\eta_{i, t b}=\left(h_{2 a, s}-h_{2 b, s}\right) /\left(h_{2 a, s}-h_{i, 2 b, s}\right)=\left(h_{2 a, s}-h_{2 c, s}\right) /\left(h_{2 a, s}-h_{i, 2 c, s}\right)$.

The output power of steam turbine $P_{t b, s}=\left(1-y_{s}\right) \dot{m}_{2, s}\left(h_{2 a, s}-h_{2 b, s}\right)+y_{s} \dot{m}_{2, s}\left(h_{2 a, s}-h_{2 c, s}\right)$.

The output power of generator $P_{g e, s}=P_{t b, s} \eta_{g e}$.

The total power of pumps $P_{p u, s}=\left(1-y_{s}\right) \dot{m}_{2, s}\left(h_{2 e, s}-h_{2 d, s}\right)+\dot{m}_{2, s}\left(h_{2 g, s}-h_{2 f, s}\right)$.

Heat injected in the water circuit $Q_{2, s}=\dot{m}_{2, s}\left(h_{2 a, s}-h_{2 g, s}\right)$.

The generator efficiency is the same of that in the cascade system, and the efficiency of Rankine cycle can be expressed as $\eta_{r k, s}=\left(P_{t b, s}-P_{p u, s} / \eta_{g e}\right) / Q_{2, s}$. 


\subsection{Stand-alone dish-Stirling system}

In the stand-alone dish-Stirling system, Stirling engines with the same number of dish collectors are directly put on the focuses of the dish collectors. Water is used for cooling the Stirling engines. $T_{H, s}$ is chosen to be equal to outlet temperature of air in dish receiver. $T_{L, S}$ is chosen to be $310 \mathrm{~K}$, the default expansion temperature in Fraser's dissertation [21] for the calculation of 4-95 NKII engine. $k$ and $\gamma$ are chosen the same value as that of the Stirling engines in the cascade system.

The power of Stirling engines $P_{\text {sea }, \mathrm{s}}=n_{d c} A_{d c} I_{r} \eta_{d c} \eta_{\text {sea }, \mathrm{s}}$.

\section{Results analysis}

The results presented in Table 3 are issued using design parameters with counterflow of two fluids in Stirling engine array as the default flow type. It is shown that the cascade system with design parameters can achieve higher efficiency compared to corresponding stand-alone systems. Although the efficiency of the Stirling engine array is lower, the efficiency of the Rankine cycle is higher. The overall output power of the cascade system is $3.83 \times 10^{4} \mathrm{~W}$ higher.

Table 3 Some important results using design parameters

\begin{tabular}{cccccc}
\hline Parameter & Value & Parameter & Value & Parameter & Value \\
\hline$\eta_{c s}$ & 0.1974 & $\eta_{\text {sea }, s}$ & 0.3786 & $P_{g e, s}$ & $5.826 \times 10^{6} \mathrm{~W}$ \\
$\eta_{s}$ & 0.1962 & $\eta_{r k}$ & 0.2660 & $P_{\text {sea }}$ & $3.552 \times 10^{5} \mathrm{~W}$ \\
$\eta_{\text {diff }}$ & 0.0062 & $\eta_{r k, s}$ & 0.2678 & $P_{\text {sea }, s}$ & $4.909 \times 10^{5} \mathrm{~W}$ \\
$\eta_{\text {sea }}$ & 0.3407 & $P_{g e}$ & $6 \times 10^{6} \mathrm{~W}$ & $P_{\text {diff }}$ & $3.830 \times 10^{4} \mathrm{~W}$ \\
\hline
\end{tabular}

\subsection{Influence of $I_{r}$}

It is found that $I_{r}$ can affect the efficiency difference of cascade system and stand-alone systems $\eta_{\text {diff. }}$ Figure 7 shows curve fits of efficiency differences $\eta_{\text {diff }}$ versus $I_{r}$ with a series of different Stirling engine array power ratios. As it can be seen, for a higher $I_{r}\left(I_{r}>550 \mathrm{~W} / \mathrm{m}^{2}\right), \eta_{\text {diff }}>0$, the cascade system can achieve a higher efficiency than corresponding stand-alone systems. For a low $I_{r}\left(I_{r}<550 \mathrm{~W} / \mathrm{m}^{2}\right), \eta_{\text {diff }}$ may be negative. In this situation, the cascade system achieves a lower efficiency than corresponding stand-alone systems. This may be explained that instead of cooling water in the stand-alone dish-Stirling system, condensed water of Rankine cycle is used to cool the Stirling engines, which jeopardises the heat dissipation and leads to a lower power of the Stirling engines. For a low $I_{r}$, the 
increased power of steam turbine due to absorbed heat by the condensed water is lower than the power loss of the Stirling engines. It can also be found that higher $I_{r}$ can achieve higher $\eta_{\text {diff, which can be interpreted as the heat }}$ absorbed by the condensed water increases with $I_{r}$. So a higher $I_{r}$ is always more suitable for cascade system. This means $I_{r}$ is a key factor to determine whether cascade system should be applied in a certain location.

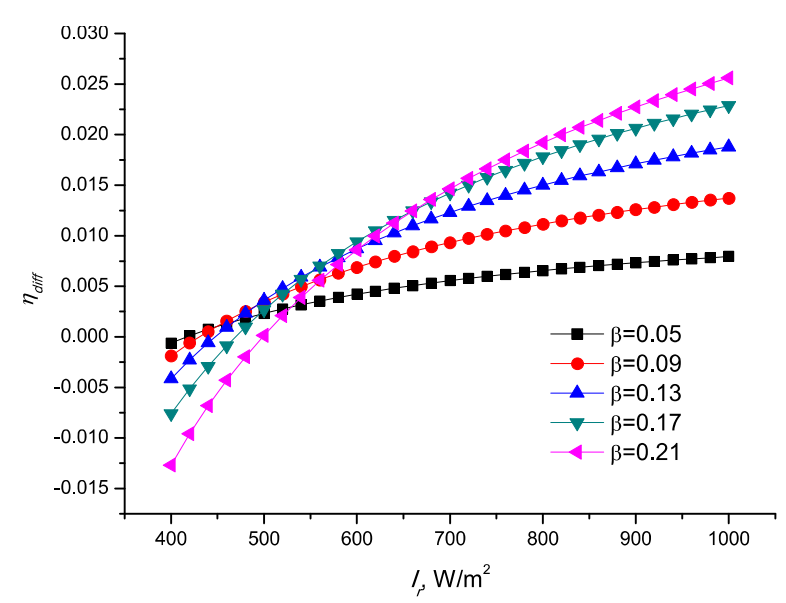

Fig. 7. Curve fits of efficiency difference $\eta_{\text {diff }}$ versus $I_{r}$

\subsection{Influence of $\beta$}

As it can be seen in Table 3, the $\eta_{\text {diff }}$ is very small with the design parameters given above. A reason $\eta_{\text {diff }}$ to be so small is that $\beta$, the ratio of power of Stirling engines to the total power, is very small, the heat released by the Stirling engine array is a small portion of the heat absorbed in the Rankine cycle. Increase $\beta$ may achieve higher $\eta_{\text {diff. }}$ The relationship between $\eta_{\text {diff }}$ and $\beta$ under a series of $I_{r}$ is shown in Fig. 8. It can be found that, for a high $I_{r}$, increase $\beta$ may

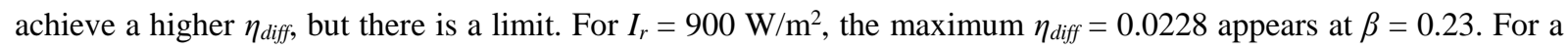
low $I_{r}, \eta_{\text {diff }}$ is negative, increase $\beta$ will reduce $\eta_{\text {diff. }}$ This can be explained for the same reason in section 5.1 . 


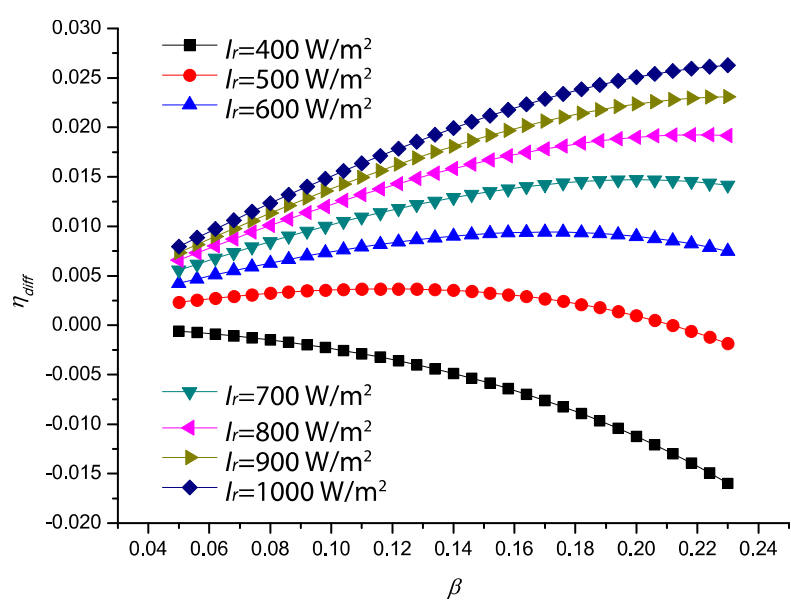

Fig. 8. Curve fits of efficiency difference $\eta_{\text {diff }}$ versus $\beta$

\subsection{Influence of flow type}

Flow type between heating and cooling streams can influence the efficiency of Stirling engine array. Parallel flow, compared to counterflow, leads to higher Stirling engine efficiency in the first columns of the array for lower cooling temperature, while lower Stirling engine efficiency in the last columns for higher cooling temperature. Table 4 shows the different results of the two flow types. The fit curves of temperature series of the heating and cooling fluids and the efficiency of Stirling engines in different columns are shown in Fig. 9.

Table 4 Results of Stirling engine array with two different flow types

\begin{tabular}{ccccccccc}
\multicolumn{8}{c}{ Table 4 Results of Stirling engine array with two different flow types } \\
\hline \multicolumn{1}{c}{ Parallel flow } & \multicolumn{5}{c}{ Counterflow } \\
\cline { 2 - 9 } & $T_{1, i}$ & $T_{2, i}$ & $P_{\text {sea }}$ & $\eta_{\text {sea }}$ & $T_{1, i}$ & $T_{2, i}$ & $P_{\text {sea }}$ & $\eta_{\text {sea }}$ \\
& $(\mathrm{K})$ & $(\mathrm{K})$ & $(\mathrm{W})$ & & $(\mathrm{K})$ & $(\mathrm{K})$ & $(\mathrm{W})$ & \\
\hline 1 & 1073.15 & 327.17 & 5000 & 0.3648 & 1073.15 & 348.09 & 4867 & 0.3601 \\
2 & 1022.38 & 329.80 & 4630 & 0.3599 & 1023.25 & 345.48 & 4541 & 0.3562 \\
3 & 974.35 & 332.29 & 4280 & 0.3544 & 975.82 & 343.00 & 4230 & 0.3520 \\
4 & 928.90 & 334.65 & 3949 & 0.3485 & 930.75 & 340.65 & 3934 & 0.3474 \\
5 & 885.91 & 336.88 & 3635 & 0.3419 & 887.94 & 338.42 & 3654 & 0.3424 \\
6 & 845.26 & 339.00 & 3338 & 0.3347 & 847.28 & 336.29 & 3387 & 0.3370 \\
7 & 806.82 & 341.00 & 3057 & 0.3269 & 808.69 & 334.28 & 3134 & 0.3312 \\
8 & 770.49 & 342.91 & 2792 & 0.3184 & 772.06 & 332.37 & 2894 & 0.3248 \\
9 & 736.16 & 344.71 & 2541 & 0.3090 & 737.31 & 330.55 & 2666 & 0.3180 \\
10 & 703.75 & 346.43 & 2304 & 0.2989 & 704.37 & 328.82 & 2450 & 0.3106 \\
\hline
\end{tabular}




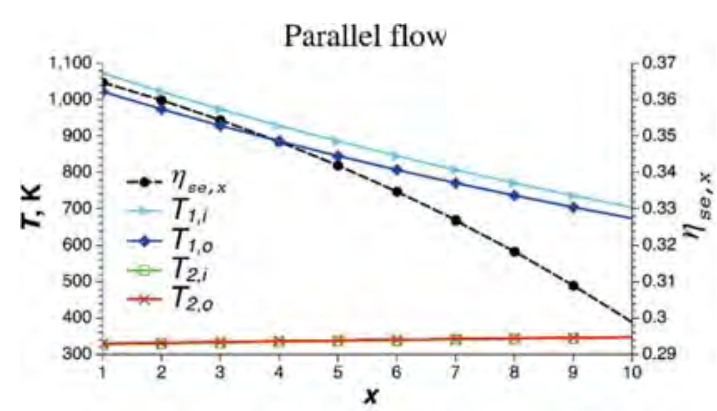

(a) Parallel flow

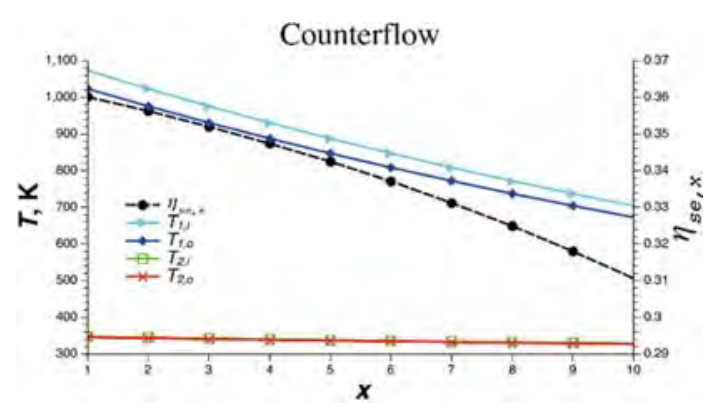

(b) Counterflow

Fig. 9. Temperature series of two fluids and efficiency of Stirling engines in column $x$

It can be concluded that the temperature increment of cooling fluid is much smaller than the temperature decrement of heating fluid due to their large difference of $c_{p} q_{m}$, which leads to a small difference of overall efficiency of Stirling engine array between the two flow types.

To find out a clear difference of the two flow types, a simple model of Stirling engine array was developed with air as the heating fluid and water as the cooling fluid. $T_{1, i}, T_{1, o}, T_{2, i}, q_{1, m}$ are fixed and chosen the same values as in the cascade system. Change the value of $q_{2, m}$, and the corresponding Stirling engine array efficiency of the two flow types ( $\eta_{p}$ and $\eta_{c}$ ) can be obtained. Figure 10 shows the efficiency of Stirling engine array with different $q_{2, m}$ in two flow types. It can be found that counterflow has a higher efficiency than parallel flow, and with lower $q_{2, m}$ comes with higher efficiency difference.

For a system with large difference of $c_{p} q_{m}$ of two fluids, that means one fluid can only achieve a small $\Delta T$ compared to the other fluid, will lead to a small difference of two flow types. For a system with similar difference of $c_{p} q_{m}$, use the counterflow can achieve a higher efficiency. 


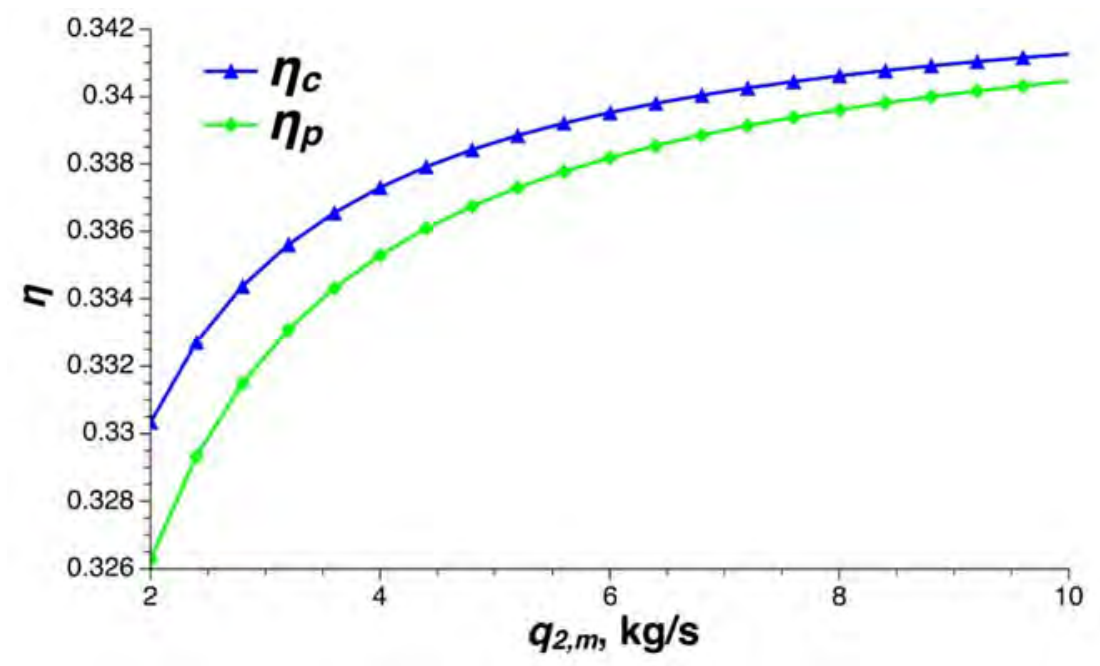

Fig. 10. Efficiency of Stirling engine array with different $q_{2, m}$

\subsection{Effect of the uncertainty of parameters on $\eta_{\text {diff }}$}

Several parameters are carefully chosen for the uncertainty analysis by using the uncertainty propagation function provided by the software EES. These parameters are critical for the efficiency of the systems. The estimated uncertainty for these parameters are given in Table 5.

Table 5 Estimation of the uncertainty of concerned parameters and their influences

\begin{tabular}{cccccc}
\hline Design parameter & $\Delta T_{3,2, \min }$ & $T_{a m b}$ & $T_{d c, o}$ & $U_{s e, 1}$ & $U_{s e, 2}$ \\
\hline Design value & $15 \mathrm{~K}$ & $293 \mathrm{~K}$ & $1073 \mathrm{~K}$ & $30 \mathrm{~W} /\left(\mathrm{m}^{2} \cdot \mathrm{K}\right)$ & $150 \mathrm{~W} /\left(\mathrm{m}^{2} \cdot \mathrm{K}\right)$ \\
Uncertainty & $\pm 1 \mathrm{~K}$ & $\pm 10 \mathrm{~K}$ & $\pm 50 \mathrm{~K}$ & $\pm 7.5 \mathrm{~W} /\left(\mathrm{m}^{2} \cdot \mathrm{K}\right)$ & $\pm 37.5 \mathrm{~W} /\left(\mathrm{m}^{2} \cdot \mathrm{K}\right)$ \\
Influence percentage & $0.0 \%$ & $0.39 \%$ & $79.43 \%$ & $18.81 \%$ & $1.37 \%$ \\
\hline
\end{tabular}

From the uncertainty results, it can be found that, using design parameters, $T_{d c, o}$ is the most influenced parameter to $\eta_{\text {diff. }}$ The result is coherent with the fact that the highest uncertainty is bounded to the temperature at the receiver outlet which affects to the Stirling engine performance.

Effect of the uncertainty of these parameters on $\eta_{\text {diff }}$ with different $I_{r}$ and $\beta$ can be found in Fig. 9 and Fig. 10. The uncertainty of the concerned parameters does not affect the rules concluded in previous sections. Higher $I_{r}$ leads to lower uncertainty of $\eta_{\text {diff }}$ may be interpreted as smaller portion of heat losses. Higher $\beta$ leads to higher uncertainty of $\eta_{\text {diff }}$ may be interpreted as the dish-Stirling assembly is more sensitive to the solar irradiation compared to the troughturbine assembly. 


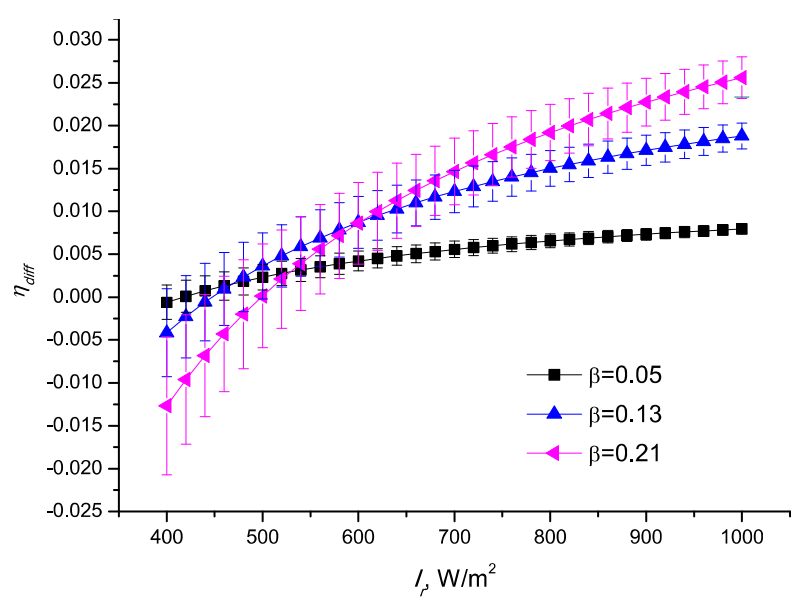

Fig. 9. Uncertainty analysis of $\eta_{\text {diff }}$ with different $I r$



Fig. 10. Uncertainty analysis of $\eta_{\text {diff with different } \beta}$

\section{Conclusion}

The model of the proposed cascade system with two different types of collectors and two different power generation methods has been developed, including different fluid circuits, with component models. Simulations were carried out and results were compared with corresponding stand-alone systems. Results show that the cascade system can achieve a higher efficiency under certain operating conditions. $I_{r}$ is the key factor to determine whether cascade system should be applied in a certain location. Compared to corresponding stand-alone systems, the cascade system can achieve a higher efficiency with high solar irradiance $\left(I_{r}>550 \mathrm{~W} / \mathrm{m}^{2}\right)$. With a high $I_{r}$, higher $\beta$ can be expected to have better results, but also comes with more uncertainty. It will be advisable to build cascade systems with a small 
number of Stirling engines to check the model and to get better results to advance in the knowledge of solar cascade systems. To design a relative cascade system including Stirling engine array, flow type of fluids for heating and cooling Stirling engine array is also required to be considered. Counterflow can achieve a higher efficiency than parallel flow. The future work will be focused on the validation and accuracy analysis of the simulation results depending on an experimental rig which is being built by our team in Wuhan, China. Besides, a cascade system with a different $\beta$ will affect the cost of the system, which is also worthy for further research.

\section{Acknowledgement}

We gratefully acknowledge the support of International S\&T Cooperation Program of China, under Grant No. 2014DFA60990, without which the present study could not have been completed. 


\section{References}

[1] World DataBank. World development indicators, 2016. [Online; accessed 22-September-2016].

[2] D.Y. Goswami. Principles of Solar Engineering, Third Edition. CRC Press, 2015.

[3] Yuanyuan Li and Yongping Yang. Thermodynamic analysis of a novel integrated solar combined cycle. Applied Energy, 122:133 - 142, 2014.

[4] Omar Behar, Abdallah Khellaf, Kamal Mohammedi, and Sabrina Ait-Kaci. A review of integrated solar combined cycle system (ISCCS) with a parabolic trough technology. Renewable and Sustainable Energy Reviews, 39(0):223-250, 2014.

[5] S Can Gülen. Second Law Analysis of Integrated Solar Combined Cycle Power Plants. Journal of Engineering for Gas Turbines and Power, 137(5):51701, 2015.

[6] S. Shaaban. Analysis of an integrated solar combined cycle with steam and organic Rankine cycles as bottoming cycles. Energy Conversion and Management, 126:1003-1012, 2016.

[7] Bandar Jubran Alqahtani and Dalia Patinõ-Echeverri. Integrated solar combined cycle power plants: Paving the way for thermal solar. Applied Energy, 169:927 - 936, 2016.

[8] Giovanni Manente. High performance integrated solar combined cycles with minimum modifications to the combined cycle power plant design. Energy Conversion and Management, 111:186 - 197, 2016.

[9] Antonio Rovira, Rubén Barbero, María José Montes, Rubén Abbas, and Fernando Varela. Analysis and comparison of integrated solar combined cycles using parabolic troughs and linear fresnel reflectors as concentrating systems. Applied Energy, 162:990-1000, 12016.

[10] Craig S. Turchi and Zhiwen Ma. Co-located gas turbine/solar thermal hybrid designs for power production. Renewable Energy, 64:172 - 179, 2014.

[11] Soumitra Mukhopadhyay and Sudip Ghosh. Solar tower combined cycle plant with thermal storage: energy and exergy analyses. Advances in Energy Research, 4(1):29-45, mar 2016.

[12] Jing Li, Pengcheng Li, Gang Pei, Jahan Zeb Alvi, and Jie Ji. Analysis of a novel solar electricity generation system using cascade Rankine cycle and steam screw expander. Applied Energy, 165:627-638, 2016.

[13] Fahad A. Al-Sulaiman. Exergy analysis of parabolic trough solar collectors integrated with combined steam and organic rankine cycles. Energy Conversion and Management, 77:441 - 449, 2014. 
[14] Seyed Saeed Bahari, Mohammad Sameti, Mohammad Hossein Ahmadi, and Mohammad Sadegh Haghgooyan. Optimisation of a combined Stirling cycle-organic Rankine cycle using a genetic algorithm. International Journal of Ambient Energy, 37(4):398-402, jul 2016.

[15] Nishith B. Desai and Santanu Bandyopadhyay. Integration of parabolic trough and linear fresnel collectors for optimum design of concentrating solar thermal power plant. Clean Technologies and Environmental Policy, 17(7):1945-1961, 102015.

[16] L. Coco-Enr' iquez, J. Muñ oz-Ant' on, and J.M. Mart' inez-Val. Integration between direct steam generation in linear solar collectors and supercritical carbon dioxide brayton power cycles. International Journal of Hydrogen Energy, 40(44):15284 - 15300, 2015. The 4th International Conference on Nuclear and Renewable Energy Resources (NURER2014), 26-29 October 2014, Antalya, Turkey.

[17] F. Formosa and G. Despesse. Analytical model for Stirling cycle machine design. Energy Conversion and Management, 51(10):1855-1863, 2010.

[18] A.J. Juhasz. A mass computation model for lightweight brayton cycle regenerator heat exchangers. In 8th Annual International Energy Conversion Engineering Conference, 2010.

[19] A. Der Minassians. Stirling Engines for Low-temperature Solar-thermal-electric Power Generation. University of California, Berkeley, 2007.

[20] M. Cavazzuti. Optimization Methods: From Theory to Design Scientific and Technological Aspects in Mechanics. Springer Berlin Heidelberg, 2012.

[21] P.R. Fraser. Stirling dish system performance prediction model. Madison, 2008.

[22] M Romero-Alvarez and E Zarza. Concentrating solar thermal power. Efficiency and Renewable Energy, 2007.

[23] W.B. Stine and R.W. Harrigan. Solar energy fundamentals and design: with computer applications. A WileyInterscience publication. John Wiley \& Sons, Incorporated, 1985.

\section{Appendix A. Thermal gradient under constant heat flux}

Assuming $U, T_{c}, \dot{m}, c_{p}$, $q$ ” to be constant, for a given $T_{i}$, 


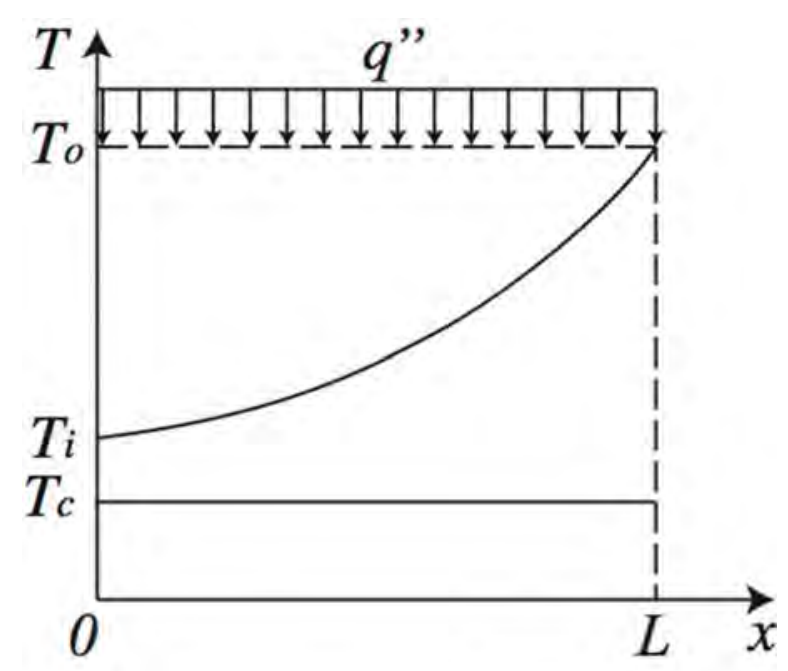

Fig. A.11: Diagram of ambient loss of a flow under constant heat flux

For $A(x)=P x, x$ from 0 to $L$, while $T(x)$ from $T_{i}$ to $T_{o}$,

$$
\dot{m} c_{p} d T(x)=\left(T_{c}-T(x)\right) U P d x+q " P d x
$$

so

$$
\frac{d T(x)}{d x}=-\frac{U P}{\dot{m} c_{p}} T(x)+\frac{q " P+U P T_{c}}{\dot{m} c_{p}}
$$

then

$$
\frac{T_{o}-T_{c}-\frac{q^{\prime \prime}}{U}}{T_{i}-T_{c}-\frac{q^{\prime \prime}}{U}}=\exp \left(-\frac{U A}{\dot{m} c_{p}}\right)
$$

when $q "=0$,

$$
\frac{T_{o}-T_{c}}{T_{i}-T_{c}}=\exp \left(-\frac{U A}{\dot{m} c_{p}}\right)
$$




\section{Appendix B. Stirling engine model}

A simple Stirling engine model is used for the system. The cycle efficiency is given by [23]

$$
\eta=\frac{T_{H}-T_{L}}{T_{H}+\frac{1-e}{k-1} \cdot \frac{T_{H}-T_{L}}{\ln \gamma}}
$$

where $e=\left(T_{R}-T_{L}\right) /\left(T_{H}-T_{L}\right), T_{R}$ is the regenerator temperature, $k=c_{p} / c_{v}$ for the working gas, $\gamma_{s e}=V_{\max } / V_{\min }$ is the compression ratio.

The heat transfer diagram is shown in Fig. B.12. Flow 1 is used for heating the hot chamber of Stirling engine, $T_{1 i}$ is the inlet temperature, $T_{1 o}$ is the outlet temperature. Flow 2 is used for cooling the cold chamber of Stirling engine, $T_{2 i}$ is the inlet temperature, $T_{2 o}$ is the outlet temperature. $T_{H}$ is the highest temperature of expansion space, $T_{L}$ is the lowest temperature of compression space.



Fig. B.12: Heat transfer diagram of Stirling engine

According to Equation (A.4),

and

$$
\frac{T_{1 o}-T_{H}}{T_{1 i}-T_{H}}=\exp \left(-\frac{U_{1} A_{1}}{\dot{m}_{1} c_{p_{1}}}\right)
$$

$$
\frac{T_{2 o}-T_{L}}{T_{2 i}-T_{L}}=\exp \left(-\frac{U_{2} A_{2}}{\dot{m}_{2} C_{p_{2}}}\right)
$$

So known $T_{1 o}, T_{1 i}, U_{1}, A_{1}, \dot{m}_{1}, c_{p 1}, T_{2 o}, T_{2 i}, U_{2}, A_{2}, \dot{m}_{2}, c_{p 2}, T_{H}$ and $T_{L}$ can be calculated, and then $\eta$ can be obtained by using Equation (B.1). 